\title{
Lipid core peptide/poly(lactic-co-glycolic acid) as a highly potent intranasal vaccine delivery system against Group A streptococcus
}

Nirmal Marasini ${ }^{\text {a }}$, Zeinab G. Khalil ${ }^{\text {b }}$, Ashwini Kumar Giddam ${ }^{\text {a }}$, Khairunnisa Abdul Ghaffar a, Waleed M. Hussein ${ }^{\text {a }}$, Robert J. Capon ${ }^{\mathrm{b}}$, Michael R. Batzloff ${ }^{\mathrm{c}}$, Michael F. Good ${ }^{\mathrm{c}}$, Mariusz Skwarczynski ${ }^{\text {a }}$, Istvan Toth ${ }^{\text {a, }}$, d*

a The University of Queensland, School of Chemistry \& Molecular Biosciences, St Lucia, QLD, 4072, Australia

$\mathrm{b}$ The University of Queensland, Institute for Molecular Biosciences, St Lucia, QLD, 4072, Australia

${ }^{\mathrm{c}}$ Griffith University, Institute for Glycomics, Gold Coast, QLD, 4222, Australia

${ }^{\mathrm{d}}$ The University of Queensland, School of Pharmacy, Woolloongabba, QLD, 4102, Australia

\section{*Corresponding author}

Professor Istvan Toth

School of Chemistry and Molecular Biosciences,

The University of Queensland,

St Lucia, QLD 4072, Australia.

Tel.: +61 733469892

Fax: +61 733654273

Email: i.toth@uq.edu.au 


\title{
Graphical abstract
}

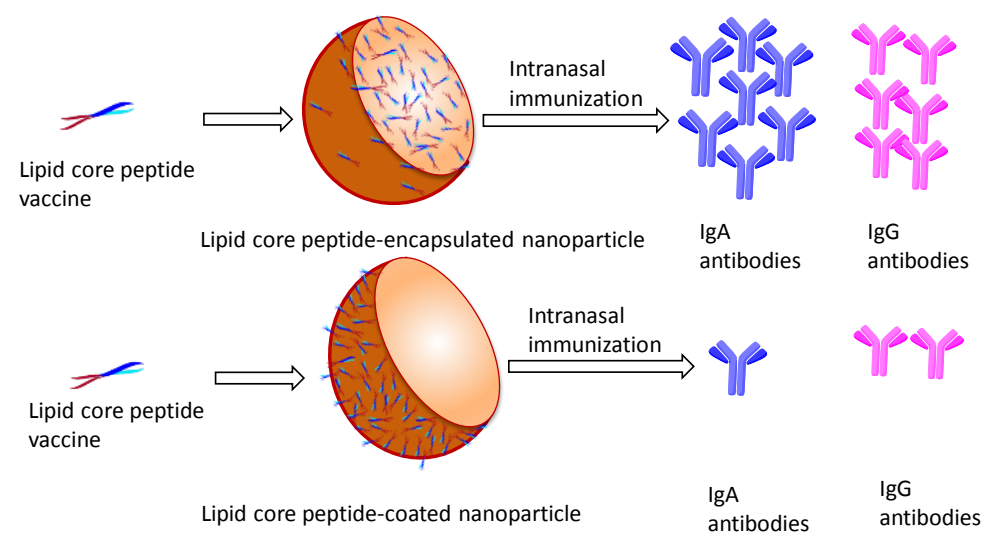

\begin{abstract}
Rheumatic heart disease represents a leading cause of mortality caused by Group A Streptococcus (GAS) infections transmitted through the respiratory route. Although GAS infections can be treated with antibiotics these are often inadequate. An efficacious GAS vaccine holds more promise, with intranasal vaccination especially attractive, as it mimics the natural route of infections and should be able to induce mucosal $\operatorname{Ig} \mathrm{A}$ and systemic $\operatorname{IgG}$ immunity. Nanoparticles were prepared by either encapsulating or coating lipopeptide-based vaccine candidate (LCP-1) on the surface of poly(lactic-co-glycolic acid) (PLGA). In vitro study showed that encapsulation of LCP-1 vaccine into nanoparticles improved uptake and maturations of antigen-presenting cells. The immunogenicity of lipopeptide incorporated PLGA-based nanoparticles was compared with peptides co-administered with mucosal adjuvant cholera toxin B in mice upon intranasal administration. Higher levels of J14-specific salivary mucosal IgA and systemic antibody IgG titres were observed for groups immunized
\end{abstract}


with encapsulated LCP-1 compared to LCP-1 coated nanoparticles or free LCP-1. Systemic antibodies obtained from LCP-1 encapsulated PLGA NPs inhibited the growth of bacteria in six different GAS strains. Our results show that PLGA-based lipopeptide delivery is a promising approach for rational design of a simple, effective and patient friendly intranasal GAS vaccine resulting in mucosal $\operatorname{IgA}$ response.

Keywords: nanoparticles; lipopeptides; PLGA; vaccine; mucosal immunology

\section{Introduction}

The primary goal of any vaccine is to induce long lasting antigen-specific immunity against the pathogens. Most pathogens invade the human body through the mucosal route. Therefore, the development of mucosal vaccines that are able to produce neutralizing antibodies to prevent pathogen colonization at the primary site of contact (mucosal tissue) is desirable (Marasini et al., 2014). Parenterally administered vaccines normally induce systemic immunity, whereas mucosally administered vaccines should be able to simultaneously stimulate both mucosal and systemic immune responses (Lycke, 2012). Parenteral vaccines using whole pathogen-based live attenuated, or killed microorganisms as antigens, are usually highly immunogenic but not necessarily completely safe. Subunit vaccines, owing to their well-defined components, are expected to cause minimal side effects and toxicity. However, antigens in subunit-based vaccines are usually poorly immunogenic and the use of adjuvants is required for vaccine efficacy (Skwarczynski and Toth, 2016). Furthermore, the immunogenicity is lower for peptide antigens delivered through the mucosal route, even when administered with adjuvant, in comparison to the standard parental immunization (Csaba et al., 2009). Cholera toxin subunit B (CTB) is the most widely used mucosal adjuvant in experimental animals; however, CTB is potentially toxic and restricted 
for animal use only. Therefore, the development of safe and efficacious mucosal adjuvants that are able to boost mucosal responses ( $\operatorname{Ig} \mathrm{A})$ is important for future clinical use.

Group A streptococcus (GAS) causes several complications such as pharyngitis, impetigo, scarlet fever, acute rheumatic fever, rheumatic heart diseases and poststreptococcal glomerulonephritis. In 2005, it was estimated that at least 18.1 million people suffered from serious GAS diseases, with 1.78 million new cases every year, causing half a million deaths each year (Carapetis et al., 2005). To reduce the global health burden of GASrelated diseases, an effective prevention approach is required. With the exceptions of healthier life-styles and easy access to health-care facilities, the development of safe, effective, and affordable vaccines is much warranted to prevent GAS-related post infection complications. GAS is often transmitted to the body from the throat, and primarily colonizes the mucosal tissue before systemic invasion in the blood. Induction of local immunity at the site of contact (nasopharyngeal tract) can be used as the first line of protection against GAS (Good et al., 2013). Thus, the nasal route is the preferred choice for vaccine administration against GAS. Lipopeptide vaccine candidate (LCP-1) incorporating minimal B-cell epitope derived from GAS M-protein called J14 and universal T-helper cell epitope (P25) was previously shown to be effective in the induction of humoral immune responses against GAS, upon systemic and intranasal administration (Fig. 1) (Abdel-Aal et al., 2008; Zaman et al., 2012). Here, we propose a nanoparticle delivery system based on PLGA to further improve immunogenicity of LCP-1 while reducing the antigen dose.

Nanoparticles (NPs) have shown huge potential as peptide/protein-based antigen carriers (Csaba et al., 2009; Skwarczynski and Toth, 2014). NPs protect the encapsulated antigens, improve their uptake by APCs, prolong interactions with antigen-presenting cells (APCs) and provide an additional danger signal to produce antigen-specific immune responses (Irvine et al., 2015). Poly (lactic-co-glycolic) acid (PLGA) is one of the more 
extensively used polymers in antigen delivery systems. PLGA is non-toxic, nonimmunogenic, biodegradable and licensed for human use by the United States Food and Drug Administration (Danhier et al., 2012). While the interactions of NPs and APCs are important for vaccine efficacy, the location of antigens in the NPs could play a crucial role in the continual recruitment of APCs as well as determining the intensity or durability and quality of immune responses. Antigens are usually encapsulated, or adsorbed on the surface of PLGA NPs (Gregory et al., 2013). Incorporation of antigens in/on PLGA NPs is mainly facilitated by hydrophobic or electrostatic interactions. Recently, Liu et al. reported that antigen-encapsulated or antigen-both encapsulated and absorbed to the surface were better in eliciting antigen-specific immune responses compared with surface-adsorbed or free antigens (Liu et al., 2016). However, some studies have reported contradictory findings where surfaceattached antigens, or adsorbed onto NPs, were shown to have better immunogenicity than antigens encapsulated into NPs (Barnier-Quer et al., 2013; Briones et al., 2001; O'Hagan et al., 2001). Those studies were based only upon parenteral immunizations, therefore, the current study compared delivery systems prepared either by encapsulation or surfaceadsorption of lipopeptide vaccines onto PLGA NPs for their ability to induce mucosal immune responses upon intranasal administration in mice model.

Lipid core peptide vaccine candidate (LCP-1, Fig.1) encapsulated in PLGA NPs (NPs-1) or LCP-1-coated PLGA NPs (NPs-2) were prepared (Fig. 2). Antigen-presenting cells (APCs) uptake of NPs and subsequent APCs' maturation were accessed. PLGA NPs efficacy in mice was compared to free LCP-1, and a mixture of peptides bearing the same antigens as LCP-1 with or without cholera toxin B (CTB). The antibodies obtained from blood were assayed for their capacity to inhibit growth of several strains of GAS bacteria.

\section{Material and methods}




\subsection{Materials}

Poly-(lactic-coglycolic-acid) (PLGA) (L: G，50:50) (Mw: 10,000-15000) was purchased from PolySciTech® (United States). Dichloromethane (DCM), poly (vinyl alcohol) (PVA) (Mw: 30,000-70,000), phenylmethylsulfonylfluoride (PMSF), soybean trypsin inhibitor, 3,3',5,5'-Tetramethylbenzidine (TMB) substrate and all other reagents were purchased at the available purity from Sigma-Aldrich (Castle Hill, NSW, Australia). Antibodies, CD11c-A660, F4/80-APC-Cy7 and FITC-CD80 were purchased from BioLegend (CA, United States). Secondary antibodies (IgG, IgG1, IgG2a and IgA) conjugated to horseradish peroxidase and CTB were purchased from sigma Aldrich (Australia).. Lysotracker® RedDND-99 was purchased from Life technologies (Victoria, Australia). All chemicals were used as received without any purification. For the opsonization assay, yeast extract was purchased from Merck, Todd-Hewitt broth from Oxoid, and horse blood from Serum Australia. Millipore water was used in all formulations or where required. Lipid core peptide vaccine candidate (LCP-1) incorporating C-16 alkyl lipids (2-amino-D,Lhexadecanoic acid) chemically conjugated by linker (Serine-Serine-Lysine) to B-cell epitope (J14, KQAEDKVKASREAKKQVEKALEQLEDKVK) and universal T-helper cell epitope (P25; KLIPNASLIENCTKAEL) were synthesized using microwave-assisted solid phase peptide synthesis (SPSS) method using Boc chemistry (Marasini et al., 2016; Skwarczynski and Toth, 2011). Further, peptides J14 and P25 were synthesized by SPSS using Fmoc chemistry (Ahmad Fuaad et al., 2016).

\subsection{Nanoparticle preparation}

A cationic amphiphilic vaccine candidate (LCP-1) (Fig. 1) and peptides J14 and P25 were synthesized and purified as described previously (Marasini et al., 2016). LCP-1 was encapsulated into PLGA using the double emulsion solvent evaporation method (NPs-1). 
Double emulsion method is widely used to encapsulate drugs and antigens (Pavot et al, 2014). Briefly, LCP-1 (1.5 mg) was added to Millipore water (1 mL). PLGA (7.5 mg) was added to DCM (3 mL). To the organic solution, aqueous LCP-1 solution was slowly added to the DCM solution under stirring, and the mixture was sonicated (Branson sonifier 250, duration $2 \mathrm{~min}$, duty cycle 50, output 4) to form a primary water-in-oil emulsion. Primary emulsion was added dropwise to $6.75 \mathrm{~mL}$ of $0.75 \%$ PVA solution forming a double emulsion (water-oil-water), then sonicated (Branson sonifier 250, duration $2 \mathrm{~min}$, duty cycle 50, output 4) and stirred overnight under atmospheric pressure to remove organic solvent (DCM). NPs1 suspensions were centrifuged at $3,000 \times g$ for $3 \mathrm{~min}$ to remove large particles. Supernatant was transferred, and centrifuged at $15,000 \times g$ for $10 \mathrm{~min}$ to collect small-size particles. The small-sized particles were further washed with Millipore water and centrifuged $(15,000 \times g$ for $10 \mathrm{~min}$ ) twice to remove non-entrapped LCP-1.

LCP-1-coated PLGA NPs (NPs-2) were prepared by the single-emulsion solvent evaporation method where empty anionic PLGA nanoparticles were initially produced following subsequent coating with cationic LCP-1. The change in surface-charge was considered as evidence for successful surface coating of particles. Briefly, PLGA (7.5 mg) in DCM (3 mL) was added dropwise to $6.75 \mathrm{~mL}$ of $0.75 \%$ PVA. Upon evaporating the DCM, LCP-1 was added to the PVA solution and stirred for $2 \mathrm{~h}$ at room temperature. NPs were collected using a similar process to that described above. Unadsorbed LCP-1 was removed after twice washing with water. Particle size and zeta potential analysis were used to monitor formation of both NPs.

\subsection{Physicochemical characterizations}

\subsubsection{Particle size distribution and zeta potentials}


The average particle size, polydispersity index (PDI) and zeta potentials of the nanoparticles were determined using dynamic light scattering (DLS) at a back scattering angle of $173{ }^{\circ} \mathrm{C}$ using a Zetasizer ( Zetasizer Nano Series ZS, Malvern Instruments, United Kingdom). The results are expressed as an average of at least three measurements for each batch.

\subsubsection{Morphology}

Transmission electron microscopy (TEM, JEOL Ltd, Japan) was used to visualize the surface morphology of the nanoparticles. A drop of the sample was placed in a glowdischarged carbon-coated grid and particles were allowed to settle in the grid for $2 \mathrm{~min}$. The excess liquid was wicked off with filter paper and particles were stained with $1 \%$ phosphotungstic acid $(\mathrm{pH}, 7)$ for $30 \mathrm{sec}$. The excess stain solution was wicked away and the grid was air-dried for 5 min before taking the microscopic image.

\subsubsection{Loading efficiency and nanoparticle yield}

The quantities of LCP-1 encapsulated or surface-adsorbed onto PLGA NPs were measured by comparing with the known concentration of LCP-1 obtained from the standard calibration curve. In brief, particles were centrifuged at $15,000 \times g$ for $20 \mathrm{~min}$. Upon formation of pellets, the supernatant was removed, filtered $(0.45 \mu \mathrm{m}$ membrane filter $)$ and measured for the content of free LCP-1 in the solution by employing reverse phase high performance liquid chromatography (RP-HPLC) using Shimadzu (Kyoto, Japan) instrumentation (DGU-20A5, LC-20AB, SIL-20ACHT, SPD-M10AVP). The flow rate was maintained at $1 \mathrm{~mL} \mathrm{~min}{ }^{-1}$, UV detection at wavelength $214 \mathrm{~nm}$ and/or evaporative light scattering detector (ELSD) using Vydac analytical C4 column (214TP54; $5 \mathrm{~mm}, 4.6 \mathrm{~mm}$ $250 \mathrm{~mm}$ ). The mobile phase comprising solvent A [0.1\% trifluroacetic acid (TFA) in water] 
and solvent $\mathrm{B}(0.1 \% \mathrm{TFA}, \mathrm{v} / \mathrm{v}$, in $90 \%$ acetonitrile $)$ in a linear gradient from $40 \% \mathrm{~A}$ in $\mathrm{B}$ to $100 \%$ B over 60 min.

Loading efficiency was calculated as the percentage of the amount of LCP-1 in the NPs divided by the total weight of NPs. Entrapment efficiency percentage was obtained upon dividing total amount of LCP-1 in NPs by the total amount of LCP-1 fed initially. The formulations were centrifuged, sediment was freeze-dried and the yield was calculated as the percentage of amount of NPs divided by the total amount of polymers and LCP-1 fed initially.

\subsection{Antigen-presenting cells uptake and maturation studies}

Single cell suspensions of spleens were physically disrupted and passed through stainless-steel mesh. Erythrocytes were lysed using red blood cell lysis buffer (Sigma Aldrich, Australia). Cells were plated with 2 × $10^{5}$ cells / well on a 96-well plate in phenolfree IMDM Glutamax medium (Gibco ${ }^{\circledR}$, Life science, CA. USA) supplemented with $10 \%$ fetal bovine serum, $50 \mu \mathrm{M}$ 2-mercaptoethanol, $100 \mathrm{U} / \mathrm{mL}$ penicillin and $100 \mu \mathrm{g} / \mathrm{mL}$ streptomycin. NPs equivalent to $2 \mu \mathrm{g}$ carboxyfluroscein-conjugated LCP-1 alone or encapsulated (NPs-1) or surface-coated onto PLGA NPs (NPs-2) were added to the each well and incubated at $37{ }^{\circ} \mathrm{C}$ for $6 \mathrm{~h}$. Cells that adhered to wells were scraped and added to $\mathrm{Fc}$ block (eBioscience, CA, USA) and incubated for $30 \mathrm{~min}$ at $4^{\circ} \mathrm{C}$. The cells were centrifuged and resuspended in a buffer containing CD11c (eBioscience CA, USA) F4/80 (BioLegend, CA, USA), CD80 (BioLegend, CA, USA) and CD86 (eBioscience CA, USA) antibodies for $30 \mathrm{~min}$ at $4{ }^{\circ} \mathrm{C}$. The cells were then centrifuged, washed and resuspended in $0.5 \mathrm{ml}$ of FACS buffer (PBS, 0.02\% sodium azide, 0.5\% BSA) using an LSR II flowcytometer (BD Biosciences). The mean fluorescence intensity positive between carboxyfluroscein-LCP-1 and $\mathrm{CD} 11 \mathrm{C}$ or $\mathrm{F} 4 / 80$ was used to quantify uptake by dendritic cells and macrophages, 
respectively. Additionally, percentage fluorescence positive for CD11C or F4/80 cells and activation markers CD80 and CD86 were used to identify the maturation of dendritic cells or macrophages.

\subsection{Confocal imaging}

Complete splenocytes were incubated for $6 \mathrm{~h}$ at $37^{\circ} \mathrm{C}$, with carboxyfluroscein-tagged LCP-1 encapsulated NPs. Cells were extensively washed and fixed with a $4 \%$ w/v paraformaldehyde solution. Lysotracker ${ }^{\circledR} 100 \mu \mathrm{L}(100 \mathrm{nM})$ was used to stain lysosomes. Stained cells were visualized under confocal microscopy (LSM710, Zeiss Co. Germany).

\subsection{Immunization study}

All studies were conducted in accordance with the National Health and Medical Research Council (NHMRC) of Australia guidelines and approved by the Institute of Ethics Review Board for animal-based work (Griffith University, GU ref no. Gly-01-15 AEC). All animals (6 weeks age) were maintained under pathogen-free conditions with free access to food and water. Female outbred ARC-Swiss mice were obtained from the animal resource centre, Perth, Western Australia. Mice were divided into 6 different cohorts with 5 mice in each group. Immunizations were performed as follow; mouse was held in supine position with head tilted down and a formulation was administered slowly using micropipette to avoid nostril blockage. Each mouse received $10 \mu \mathrm{g}$ LCP-1 alone or NPs bearing $10 \mu \mathrm{g} \mathrm{LCP}-1$ at a volume of $10 \mu \mathrm{L}(5 \mu \mathrm{L} /$ nostril). Positive control groups received a mixture of peptides incorporating B cell epitope, J14 (20 $\mu \mathrm{g})$ and universal T-helper cells epitope, P25 (20 $\mu \mathrm{g})$ adjuvanted with CTB $(10 \mu \mathrm{g})$. Additionally, another control group received similar formulations but without CTB. The negative control group received PBS at a total volume of $10 \mu \mathrm{L}(5 \mu \mathrm{L} /$ nostril) for each mouse. Mice were immunized three times at 2 -week intervals (Day 1, 14 and 28). 


\subsubsection{Sample collections}

Blood samples were collected from a tail artery bleed on day 28 and 42. Sera was separated after centrifuging at $10,000 \times g$ for $10 \mathrm{~min}$. Saliva samples were collected upon intraperitoneal injection of pilocarpine solution $(50 \mu \mathrm{L})$. Saliva was collected in a tube prefilled with $1 \mu \mathrm{L}$ of protease inhibitor [100 mM phenylmethylsulfonylfluoride (PMSF)]. Both sera and salivary samples were stored immediately at $-80{ }^{\circ} \mathrm{C}$ until further analysis.

\subsubsection{ELISA}

The sera and saliva from the immunized mice were tested for the presence of antibodies (IgG, IgG1, IgG2a and IgA) by the ELISA method as described earlier (Ghaffar et al., 2016). Briefly, microtitre plates (96-well) were coated with $50 \mu \mathrm{g}$ of J14 antigen per plate prepared in carbonate-coating buffer ( $\mathrm{pH}$ 9.6) followed by incubation at $37{ }^{\circ} \mathrm{C}$ for $90 \mathrm{~min}$. The plates were washed with PBS-tween (PBST) (0.05\%) mixture and then blocked with 5\% skim milk in PBST solution overnight at $4{ }^{\circ} \mathrm{C}$. The plates were washed, the sample added and two-fold serial dilution at a starting dilution of 1:200 (for serum $\operatorname{IgG}$ ), 1:100 (serum $\operatorname{IgG}$ subtypes) and 1:4 (salivary IgA) for the sample for each mouse was performed. The plates were incubated at $37^{\circ} \mathrm{C}$ for $90 \mathrm{~min}$ and then washed with PBST. Secondary antibodies (IgG, $\operatorname{IgG1}, \operatorname{IgG} 2 \mathrm{a}$ and $\operatorname{Ig} \mathrm{A})$ conjugated to horseradishperoxidase were added to the plates and incubated at $37{ }^{\circ} \mathrm{C}$ for $90 \mathrm{~min}$. Plates were washed, and combined with TMB substrate and then further incubated at room temperature for $20 \mathrm{~min}$ for colour development. The reactions were stopped using $2 \mathrm{M} \mathrm{H}_{2} \mathrm{SO}_{4}$ and the absorbance was measured at $450 \mathrm{~nm}$ using a microplate reader (Spectramax, United States). Results were expressed as the end-point dilution that gave an absorbance of three standard deviations above the mean absorbance of control wells (sera/saliva from naïve unimmunized mice). The levels of antibody titres are expressed in $\log 10$ and $\log 2$ scale to represent $\operatorname{IgG} / \operatorname{IgG} 1 / \operatorname{IgG} 2 \mathrm{a}$ and $\operatorname{Ig} \mathrm{A}$, respectively. 


\subsection{Indirect bactericidal assay}

Mouse anti-J14 peptide sera samples were analysed for their ability to opsonize GAS in an indirect bactericidal assay as previously described with slight modification (Brandt et al., 2000). Different hospital strains of GAS (Streptococcus pyogens) were tested (Table 1). The bacterium to be tested was streaked on a Todd-Hewitt broth (THB) supplemented with $5 \%$ yeast extract agar plate, and incubated at $37{ }^{\circ} \mathrm{C}$ for $24 \mathrm{~h}$. A single colony was transferred to fresh THB $(5 \mathrm{~mL})$ supplemented with $5 \%$ yeast extract and grown overnight at $37{ }^{\circ} \mathrm{C}$ to give approximately $4.6 \times 10^{6}$ colony forming units (CFU) $/ \mathrm{mL}$. The culture was serially diluted to $10^{-2}$ in PBS from which an aliquot $(10 \mu \mathrm{L})$ was mixed with fresh heat-inactivated sera $(10 \mu \mathrm{L})$ and horse blood $(80 \mu \mathrm{L})$. Inactivated sera were prepared by heating in a water bath at $50{ }^{\circ} \mathrm{C}$ for $30 \mathrm{~min}$. Bacteria were grown in the presence of sera and incubated in a 96well plate at $37{ }^{\circ} \mathrm{C}$ for $3 \mathrm{~h}$. To analyse bacterial survival, culture material $(10 \mu \mathrm{L})$ was plated on Todd-Hewitt agar plates supplemented with 5\% yeast extract and 5\% horse blood. Plates were incubated at $37{ }^{\circ} \mathrm{C}$ for $24 \mathrm{~h}$ and colonies enumerated to $\mathrm{CFU}$. Opsonic activity of the antibodies (anti-peptide) sera (\% reduction in mean CFU) was calculated as [1-(CFU in the presence of anti-peptide sera)/ (mean CFU in the presence of PBS)] x 100. The assay was performed in triplicate from three independent cultures.

\subsection{Statistical analysis}

Statistical analysis was performed using one-way ANOVA and post-hoc Tukey test using GraphPad Prism (version 6). $P$ values of $<0.05(*),<0.01(* *),<0.001(* * *)$ and $<0.0001(* * * *)$ were used to indicate statistical significance among the groups.

\section{Results}

\subsection{Preparation and Characterizations of NPs}


A cationic amphiphilic vaccine candidate (LCP-1) (Fig. 1) and peptides J14 and P25 were synthesized in a high purity (>95\%). NPs-1 were prepared using double-emulsion method, while NPs-2 were prepared by single-emulsion method followed by subsequent coating with LCP-1 (Fig.2). The amount of stabilizer (PVA) and the ratio of LCP-1 to PLGA were optimized-based on size and PDI measurements (Fig.S1 and S2). The NPs that were prepared at a ratio of LCP-1 to PLGA 1: 5 with PVA as a stabilizer at a concentration of 0.75\% showed the lowest particle size and PDI, and were selected for further study (Fig.S1 and S2). The hydrophobic PLGA polymer formed particles entrapping LCP-1 inside the cores (NPs-1); however the presence of some LCP-1 molecules on the surface of the PLGA NPs could not be excluded (Fig. 2C). To prepare NPs-2, cationic LCP-1 was added to empty anionic PLGA NPs dispersions. LCP-1 was adsorbed on the surface of PLGA NPs via hydrophobic and electrostatic interactions between anionic PLGA and cationic LCP-1 (Fig. 2D). We used a two-stage partial centrifugation technique to separate smaller particles from the larger particles. NPs suspended into PVA solutions were first subjected to low speed centrifugation at $3,000 \times g$ for $3 \mathrm{~min}$. Then, the large-sized particles were discarded and supernatants were subjected to a second-stage centrifugation at $15,000 \times g$ for 10 min to isolate small particles. The free/unencapsulated/uncoated LCP-1 in NPs was removed upon twice washing with water. The mean particle size as measured by DLS showed monodispersed particles for empty NPs, LCP-1-encapsulated NPs (NPs-1) and LCP-1-coated NPs (NPs-2) with diameter approximately $205 \mathrm{~nm}, 198 \mathrm{~nm}$, and $219 \mathrm{~nm}$, respectively (Table 2). Representative TEM images of NPs-1 and NPs-2 showed well-defined spherical-shaped particles with narrow-sized distributions and size-consistency to DLS measurements (Fig. 3). The zeta potentials observed for empty NPs, NPs- 1 and NPs- 2 were approximately $-33 \mathrm{mV}, 8$ $\mathrm{mV}$ and $-4 \mathrm{mV}$, respectively (Table 2). The net negative charge of NPs-2 is attributed to their low entrapment efficiency of cationic LCP-1 on the surface of NPs as compared to NPs-1 
(Table 2). The typical yield of particles upon the two-stage centrifugation technique was $6 \%$ (Table 2). Similar yields for the two-stage centrifugation method were previously reported (Zhou et al., 2013). DLS measurement obtained after re-dispersion of pellets following a single-stage centrifugation process $(3,000 \times g)$ showed highly polydispersed empty NPs, NPs-1 and NPs-2 with size approximately $470 \mathrm{~nm}, 750 \mathrm{~nm}$ and $521 \mathrm{~nm}$, respectively. These larger particles were then discarded and never used (Table S1). Entrapment efficiencies of LCP-1 into NPs-1 and NPs-2 were approximately $71 \%$ and $30 \%$, respectively, while the final loading capacities of LCP-1 in NPs-1 and NPs-2 were approximately $28 \%$ and $12 \%$, respectively (Table 2 ).

\subsection{Cellular uptake by antigen-presenting cells and subsequent maturation}

Splenocytes were harvested from naïve mice and stimulated with carboxyflurosceinconjugated LCP-1 bearing NPs. The treated DCs and macrophages were tagged with CD11c (the surface marker of DCs) and F4/80 (specific markers for murine macrophages) antibodies, respectively. Significantly higher numbers of APCs had taken up free LCP-1 or LCP-1 present in NPs-1 and NPs-2 compared to the group stimulated with PBS (Fig. 4 A and B). Among the studied groups, cationic LCP-1 showed the highest level of uptake by APCs. Although both NPs (NPs-1 vs NPs-2) possessed similar particle size, antigens encapsulated into the particles (NPs-1) were better taken up than antigens adsorbed on the surface of the particles (NPs-2) (Fig. 4A and B). The higher uptake of cationic NPs-1 (7.7 mV) compared to anionic NPs-2 $(-4.5 \mathrm{mV})$ could be due to favourable interactions between the negatively charged membrane of APCs populations and positively-charged NPs-1 particles (Fig. 4A and B). However, it is important to note that the differences in antigen uptake by APC between the groups were not statistically significant. The efficiency of LCP-1 uptake by complete splenocytes population when encapsulated into NPs was further verified by fluorescence 
microscopy images as indicated by the co-localized signal (yellow) between the green signal from carboxyfluroscein-LCP-1 and the red signal from endosomes (Fig. 4 C).

Free LCP-1 did not induce significant maturations of APCs as indicated by low levels of maturation markers CD80 and CD86 (Fig. 5). The cationic LCP-1 encapsulated NPs (NPs1) which were readily taken up by APCs showed significantly higher upregulation of both maturations markers (CD80 and CD86) by APCs than free LCP-1 and PBS-treated groups (Fig. 5). The cationic NPs-1 expressed significantly higher levels of CD $80^{+}$markers in DCs and macrophages when compared to NPs-2 (Fig. 5 A and B).

\subsection{Mucosal immunization study}

To compare the influence of different NPs on antibody responses, mucosal immunization studies were conducted in Swiss out-bred mice. Each mouse was administered with either $10 \mu \mathrm{g}$ free LCP-1 or $10 \mu \mathrm{g}$ equivalents of LCP-1 $(5 \mu \mathrm{L} /$ nostril $)$ encapsulated (NPs-1) or surface-coated NPs (NPs-2) by intranasal route every two weeks.

After the second immunizations, mice administered with LCP-1 encapsulated NPs (NPs-1) showed a significant increase in J14-specific salivary IgA antibody titres compared to the PBS administered group (Fig. 6 A). Cationic NPs-1 showed significantly higher salivary antibody titres than LCP-1-coated NPs (NPs-2). Additionally, mice groups immunized with NPs-1 showed significantly higher J14-specific serum antibody titres as compared to the PBS administered group (Fig. 6 B). Although the NPs-1 group showed higher IgG titres than NPs-2, the difference was not statistically significant.

Upon third immunizations, we observed significantly higher levels of salivary IgA antibody titres for LCP-1 encapsulated into NPs (NPs-1) compared with the PBSadministered group (Fig. 6 C). The lead NPs-1 showed significantly higher antibody titres than groups immunized with free LCP-1, physical mixture of peptides adjuvanted with CTB, 
and NPs-2. Mice immunized with LCP-1-coated on the surface of NPs (NPs-2) didn't show significant improvement in salivary immune responses even after three immunizations despite the amount of antigen (LCP-1) being standardized (the same) for all tested delivery systems (Fig. 6 A and C). Physical mixtures of peptides adjuvanted with CTB upon three immunizations showed higher immune responses compared to two immunizations (Fig. $6 \mathrm{~A}$ and C). Mice administered with free LCP-1 or physical mixtures of peptides epitopes showed poor salivary IgA antibody production even after three immunizations (Fig. $6 \mathrm{C}$ ). Mice immunized with a physical mixture of peptides adjuvanted with CTB and NPs-1 showed significantly higher J14-specific serum antibody titres than mice immunized with PBS (Fig. 6 D). In particular, mice immunized with NPs-2 showed significantly higher systemic IgG titres compared to free LCP-1 and NPs -1 (Fig. 6 D). In contrast, mice administered with NPs-2 produced poor systemic IgG responses. The lead NPs-1 was accessed for its capacity to polarize either T-helper 1(Th1) or T-helper 2 (Th2) biased immune responses. Therefore, IgG isotypes [IgG1: directed by Th2 cells and $\operatorname{IgG} 2 \mathrm{a}$ : directed by Th1 cells) antibodies were measured using serum obtained after three immunizations. NPs-1 showed mixed Th1/Th2 responses and was mostly biased towards the Th2 polarized immune response (Fig. 7).

\subsection{Indirect bactericidal assay}

Antibodies produced upon immunization with NPs-1, and the positive and negative control groups were tested for their ability to opsonize different strains of GAS, including clinical isolates. Both sera that were derived from NPs-1 and CTB $+\mathrm{J} 14+\mathrm{P} 25$ groups showed significant levels of GAS opsonization when compared with sera derived from the mice group treated with PBS (Fig. 8). The average opsonic activity of sera in different GAS bacterial strains obtained from the NPs-1 group ranged from $24.3 \%$ to $95 \%$ while sera derived from peptides adjuvanted with the CTB group resulted in $46 \%$ to $78 \%$ of 
opsonization among tested GAS strains (Fig. 8). Importantly, NPs-1 group showed similar level of opsonic activity as positive control group (CTB+J14+P25).

\section{Discussion}

GAS-related diseases, particularly rheumatic fever and rheumatic heart disease remain a great public health burden especially in developing countries and in the indigenous communities of developed countries. An effective vaccine can prevent the occurrence of GAS-related post-infection complications; however, currently there is no vaccine available to combat these bacteria. GAS colonizes the nasopharyngeal mucosa before it invades the body systemically. Therefore an ideal vaccine is expected to produce mucosal antibodies (IgA) at the site of infection and systemic antibodies in the circulations (IgG) to clear infection. The conserved peptide-based epitopes (e.g., J14) derived from the most virulent GAS cell surface M-protein are promising antigens for GAS vaccine development. However, peptide epitopes are poorly immunogenic and require co-administration with adjuvants or a delivery system (Batzloff et al., 2005; Zaman et al., 2014). Lipopeptide incorporating two copies of lipoaminoacids (2- [R/S-tert-butoxycarbonyl)] amino hexadecanoic acid), GAS-derived Bcell (J14) and universal T-helper cell (P25) epitopes is a promising vaccine candidate against

GAS infection (LCP-1, Fig. 1) (Zaman et al., 2012). Upon intranasal immunization with LCP-1 at a dose of $60 \mu \mathrm{g}$ per mouse, high levels of protective antigen-specific antibody titres were detected in mice models (Zaman et al., 2012; Zaman et al., 2014). The efficacy of this vaccine candidate was further improved upon by incorporation into liposomes (Ghaffar et al., 2016). However, liposome possesses several limitations such as low stability due to vesicles merging, enzymatic digestions and premature leaking of antigens that compromise efficacy of nasally administered antigens (Ma et al., 2011). Therefore, a more stable and potent delivery systems is required. Recently, NPs have emerged as a successful platform for vaccine 
delivery as they are biocompatible and able to improve the recognition and activation of antigens by immune systems (Irvine et al., 2015; Skwarczynski and Toth, 2014). Antigens can be encapsulated, adsorbed or conjugated to the surface of the NPs. While there is no doubt that formulations of antigens into NPs has the potential to enhance immune responses, the ideal antigen loadings methods could play a substantial role in determining the efficacy of antigen-specific immune responses. Therefore, immune responses after intranasal administration of lipopeptide vaccine into PLGA NPs as an antigen delivery vehicle were investigated by varying the antigen-loading method.

An anionic PLGA polymer formulated as NPs can incorporate cationic LCP-1 vaccine candidate inside (NPs-1), or alternatively, LCP-1 can be adsorbed on the surface of NPs (NPs-2) (Fig. 2). This incorporation is mediated by electrostatic interactions and hydrophobic interactions between PLGA and LCP-1. Indeed, lipopeptides encapsulation efficacy, especially for NPs-1, was high in comparison with the typical encapsulation efficiency of non-lipidated peptides (Lutsiak et al., 2002). For comparison, we prepared both NPs with similar compositions, identical size and shape. Particle size plays a critical role in determining the potency of immune responses. Small-sized monodispersed PLGA NPs ( 200 $\mathrm{nm})$ were better in crossing the nasal mucosal surface than micron-sized particles $(1.5 \mu \mathrm{m})$ (Vila et al., 2005). Additionally, APCs preferentially take small particles and small particles can even travel to a draining lymph node without the help of peripheral APCs to induce stronger immune responses (Foged et al., 2005; Oyewumi et al., 2010; Skwarczynski and Toth, 2014). We used the two-stage partial centrifugation technique to ensure monodispersed small-sized nanoparticles were isolated to prepare a vaccine delivery system suitable for in vivo intranasal immunization study (Table 2) (Fig. 3).

Dendritic cells (DCs) and macrophages are subsets of professional antigen presenting cells (APCs) which play a key role in the initiation and regulation of adaptive immune 
responses. Upon encountering antigens, immature APCs differentiate into matured cells and present antigen to T-lymphocytes. This process is accompanied by the up-regulation of the co-stimulatory molecules such as CD80 and CD86 which is a benchmark for effective APCs' maturation (Gong et al., 2015). Therefore, the uptake of NPs by APCs and their subsequent maturation capacity was accessed. Both PLGA-based NPs and free LCP-1 were highly taken up by APCs (Fig. 4). Interestingly, in spite of high uptake efficiency of free LCP-1 by APCs, LCP-1 alone was a poor inducer of APCs' maturations (Fig. 5). A similar result was previously reported where even the high uptake (100\%) of PLGA NPs encapsulating MART127-35 peptide was unable to improve DC maturations (Ma et al., 2011). Conversely, NPs-1 showed enhanced uptake by APCs (DCs and macrophages) and higher expression of maturation markers than NPs-2 (Fig. 4 and 5). Improved maturation of APCs could be due to the prevention of peptide degradation, high LCP-1 entrapment efficiency, and prolonged antigen presentation to APCs (Pavot et al., 2014). It was observed that APCs preferentially take up particles based on their surface-charge, and cationic-charged particles (Free LCP-1 and NPs-1) are more favored by APCs than anionic particles (Fig. 4). Thus, uptake efficacy was charge-related while maturation of APCs was independent of the surface charge of NPs. Higher uptake by APCs doesn't always guarantee initiation of immune responses (Slutter et al., 2009). After encountering antigens, only matured APCs activate T-lymphocyte proliferation to stimulate antibody responses. Our results showed that antigens encapsulated into polymeric particles with selective characteristics (e.g., cationic charge, nanosized particles) are beneficial for regulating the immune reaction cascade through the triggering of APCs' maturation.

An intranasal immunization study was performed in Swiss outbred mice. Simple physical mixtures of peptide epitopes $(\mathrm{J} 14+\mathrm{P} 25)$ did not induce any humoral immune responses as expected (Fig. 6). Higher systemic and mucosal J14-specific antibody titres were 
produced in the mice groups administered with NPs-1 compared with free LCP-1 or NPs-2 (Fig. 6). Thus, antibody productions were mostly independent on the uptake efficacy of particles by APCs and dependent upon particles' capacity to induce APCs' maturation. Poor antibody responses of NPs-2 could be due to spontaneous shedding of lipopeptide antigens from the surfaces of PLGA NPs (Hanson et al., 2014). It can be assumed that NPs-1 released LCP-1 in APC's endosomes while NPs-2 may release the antigen also before its uptake by APCs (Liu et al., 2015). The low immunogenicity of free LCP-1 was most likely related to the low dose of LCP-1 (10 $\mu \mathrm{g} /$ mouse) selected for this study. In contrast, much higher doses (e.g., $60 \mu \mathrm{g} / \mathrm{mouse}$ ) were reported previously to achieve significant immune responses (Abdel-Aal et al., 2010; Zaman et al., 2012; Zaman et al., 2014). Additionally, NPs-1 was even more efficient or comparable to the positive control group (epitopes co-administered with CTB) in producing salivary $\operatorname{IgA}$ and serum IgG antibody titres (Fig. 6). These observations were in line with the results from APCs' uptake and subsequent maturation experiments. Protections against GAS at systemic sites have been correlated with their ability to recognize and opsonize the bacteria. In vitro opsonic activities (bactericidal) of mice sera obtained from the NPs-1 group against different GAS strains showed significantly higher opsonizations up to $95 \%$ in clinical-isolates, as compared to PBS-treated groups (Fig. 8). In contrast, opsonization capacity in wild-type GAS strains from sera obtained after immunization with LCP-1 at a dose of $60 \mu \mathrm{g}$ per mouse showed only a 33\% reduction in CFU (Zaman et al., 2012).

All of the above evidences indicated that intranasal administration of LCP-1 vaccine encapsulated into PLGA NPs could provide improved mucosal and systemic immune responses compared to free LCP-1 and surface-adsorbed LCP-1 PLGA NPs. It can be assumed that NPs-1 provided a slow or prolong exposure of LCP-1 by releasing LCP-1 in APCs endosomes while LCP-1 from NPs-2 might have released before their uptake by APCs 
(Liu et al., 2015). Importantly, J14-specific mucosal and systemic antibody titres were shown to be related to protection capacity against GAS in vitro (Batzloff et al., 2005; Zaman et al., 2012).

\section{Conclusion}

The rational use of PLGA-based NPs as a delivery platform for lipopeptide-based vaccines against GAS was demonstrated. Lipopeptide vaccines encapsulated within NPs elicited stronger antigen-specific systemic IgG and mucosal IgA immune responses than free lipopeptides or lipopeptides-coated NPs at a low dose $(10 \mu \mathrm{g} / \mathrm{mouse})$, signifying the importance of encapsulation of lipopeptide vaccines into the NPs. Additionally, the systemic antibodies produced in the mice group immunized with lipopeptides-encapsulated NPs were able to opsonize up to $95 \%$ of clinical strains of GAS. Improved immune response against GAS in the mice model was associated with the efficient uptake and subsequent maturation by APCs. Thus PLGA nanoparticles seem to be a very effective self-adjuvanting delivery platform for lipopeptide-based vaccines.

\section{Acknowledgements}

The authors acknowledge the facilities, and the scientific and technical assistance of the Australian Microscopy \& Microanalysis Research Facility at the Centre for Microscopy and Microanalysis, The University of Queensland. We acknowledge A. D. Paterson and P. Harris (The University of Queensland Centre for Clinical Research) for providing Streptococcus isolates, GC 2 203, D3840 and D2612.

Author, Nirmal Marasini is a recipient of an international postgraduate research scholarship (IPRS) and Australian postgraduate award (APA) for his PhD study. This work 
was supported by the National Health and Medical Research Council [NHMRC Program Grant 496600].

\section{References}

Abdel-Aal, A.B., Batzloff, M.R., Fujita, Y., Barozzi, N., Faria, A., Simerska, P., Moyle, P.M., Good, M.F., Toth, I., 2008. Structure-activity relationship of a series of synthetic lipopeptide self-adjuvanting group a streptococcal vaccine candidates. Journal of medicinal chemistry $51,167-172$.

Abdel-Aal, A.B., Zaman, M., Fujita, Y., Batzloff, M.R., Good, M.F., Toth, I., 2010. Design of three-component vaccines against group A streptococcal infections: importance of spatial arrangement of vaccine components. Journal of medicinal chemistry 53, 8041-8046.

Ahmad Fuaad, A.A., Skwarczynski, M., Toth, I., 2016. The Use of Microwave-Assisted Solid-Phase Peptide Synthesis and Click Chemistry for the Synthesis of Vaccine Candidates Against Hookworm Infection. Methods in molecular biology 1403, 639-653.

Barnier-Quer, C., Elsharkawy, A., Romeijn, S., Kros, A., Jiskoot, W., 2013. Adjuvant Effect of Cationic Liposomes for Subunit Influenza Vaccine: Influence of Antigen Loading Method, Cholesterol and Immune Modulators. Pharmaceutics 5, 392-410.

Batzloff, M.R., Yan, H., Davies, M.R., Hartas, J., Lowell, G.H., White, G., Burt, D.S., Leanderson, T., Good, M.F., 2005. Toward the development of an antidisease, transmissionblocking intranasal vaccine for group a streptococcus. The Journal of infectious diseases 192, $1450-1455$.

Brandt, E.R., Sriprakash, K.S., Hobb, R.I., Hayman, W.A., Zeng, W., Batzloff, M.R., Jackson, D.C., Good, M.F., 2000. New multi-determinant strategy for a group A 
streptococcal vaccine designed for the Australian Aboriginal population. Nature medicine 6, 455-459.

Briones, M., Singh, M., Ugozzoli, M., Kazzaz, J., Klakamp, S., Ott, G., O'Hagan, D., 2001. The preparation, characterization, and evaluation of cationic microparticles for DNA vaccine delivery. Pharmaceutical research 18, 709-712.

Carapetis, J.R., Steer, A.C., Mulholland, E.K., Weber, M., 2005. The global burden of group A streptococcal diseases. The Lancet Infectious Diseases 5, 685-694.

Csaba, N., Garcia-Fuentes, M., Alonso, M.J., 2009. Nanoparticles for nasal vaccination. Advanced drug delivery reviews 61, 140-157.

Danhier, F., Ansorena, E., Silva, J.M., Coco, R., Le Breton, A., Preat, V., 2012. PLGA-based nanoparticles: an overview of biomedical applications. Journal of controlled release 161, 505522.

Foged, C., Brodin, B., Frokjaer, S., Sundblad, A., 2005. Particle size and surface charge affect particle uptake by human dendritic cells in an in vitro model. International Journal of Pharmaceutics 298, 315-322.

Ghaffar, K.A., Marasini, N., Giddam, A.K., Batzloff, M., Good, M., Skwarczynski, M., Toth, I., 2016. Liposome-based Intranasal Delivery of Lipopeptide Vaccine Candidates Against Group A Streptococcus. Acta Biomaterialia.(early online) 41,161-168.

Gong, H., Xiang, J., Xu, L., Song, X., Dong, Z., Peng, R., Liu, Z., 2015. Stimulation of immune systems by conjugated polymers and their potential as an alternative vaccine adjuvant. Nanoscale 7, 19282-19292.

Good, M.F., Batzloff, M.R., Pandey, M., 2013. Strategies in the development of vaccines to prevent infections with group A streptococcus. Human vaccines \& immunotherapeutics 9, 2393-2397. 
Gregory, A.E., Titball, R., Williamson, D., 2013. Vaccine delivery using nanoparticles. Frontiers in Cellular and Infection Microbiology 3, 13.

Hanson, M.C., Bershteyn, A., Crespo, M.P., Irvine, D.J., 2014. Antigen Delivery by LipidEnveloped PLGA Microparticle Vaccines Mediated by in Situ Vesicle Shedding. Biomacromolecules 15, 2475-2481.

Irvine, D.J., Hanson, M.C., Rakhra, K., Tokatlian, T., 2015. Synthetic Nanoparticles for Vaccines and Immunotherapy. Chemical reviews 115, 11109-11146.

Liu, L., Ma, P., Wang, H., Zhang, C., Sun, H., Wang, C., Song, C., Leng, X., Kong, D., Ma, G., 2016. Immune responses to vaccines delivered by encapsulation into and/or adsorption onto cationic lipid-PLGA hybrid nanoparticles. Journal of controlled release 225, 230-239

Liu, Q., Chen, X., Jia, J., Zhang, W., Yang, T., Wang, L., Ma, G., 2015. pH-Responsive Poly(d,l-lactic-co-glycolic acid) Nanoparticles with Rapid Antigen Release Behavior Promote Immune Response. ACS nano 9, 4925-4938

Lutsiak, M.E., Kwon, G.S., Samuel, J., 2002. Analysis of peptide and lipopeptide content in liposomes. Journal of pharmacy \& pharmaceutical sciences 5, 279-284.

Lycke, N., 2012. Recent progress in mucosal vaccine development: potential and limitations. Nature Reviews Immunology 12, 592-605.

Ma, W., Smith, T., Bogin, V., Zhang, Y., Ozkan, C., Ozkan, M., Hayden, M., Schroter, S., Carrier, E., Messmer, D., Kumar, V., Minev, B., 2011. Enhanced presentation of MHC class Ia, Ib and class II-restricted peptides encapsulated in biodegradable nanoparticles: a promising strategy for tumor immunotherapy. Journal of translational medicine 9,34 .

Marasini, N., Giddam, A.K., Ghaffar, K.A., Batzloff, M.R., Good, M.F., Skwarczynski, M., Toth, I., 2016. Multilayer engineered nanoliposomes as a novel tool for oral delivery of lipopeptide-based vaccines against group A Streptococcus. Nanomedicine (London) 11, 1223-1236. 
Marasini, N., Skwarczynski, M., Toth, I., 2014. Oral delivery of nanoparticle-based vaccines. Expert review of vaccines 13, 1361-1376.

O'Hagan, D., Singh, M., Ugozzoli, M., Wild, C., Barnett, S., Chen, M., Schaefer, M., Doe, B., Otten, G.R., Ulmer, J.B., 2001. Induction of Potent Immune Responses by Cationic Microparticles with Adsorbed Human Immunodeficiency Virus DNA Vaccines. Journal of Virology 75, 9037-9043.

Oyewumi, M.O., Kumar, A., Cui, Z., 2010. Nano-microparticles as immune adjuvants: correlating particle sizes and the resultant immune responses. Expert review of vaccines 9, 1095-1107.

Pavot, V., Berthet, M., Resseguier, J., Legaz, S., Handke, N., Gilbert, S.C., Paul, S., Verrier, B., 2014. Poly(lactic acid) and poly(lactic-co-glycolic acid) particles as versatile carrier platforms for vaccine delivery. Nanomedicine (London) 9, 2703-2718.

Skwarczynski, M., Toth, I., 2011. Lipid-core-peptide system for self-adjuvanting synthetic vaccine delivery. Methods in molecular biology 751, 297-308.

Skwarczynski, M., Toth, I., 2014. Recent advances in peptide-based subunit nanovaccines. Nanomedicine (London) 9, 2657-2669.

Skwarczynski, M., Toth, I., 2016. Peptide-based synthetic vaccines. Chemical Science 7, $842-854$.

Slutter, B., Plapied, L., Fievez, V., Sande, M.A., des Rieux, A., Schneider, Y.J., Van Riet, E., Jiskoot, W., Preat, V., 2009. Mechanistic study of the adjuvant effect of biodegradable nanoparticles in mucosal vaccination. Journal of controlled release 138, 113-121.

Vila, A., Sánchez, A., Évora, C., Soriano, I., McCallion, O., Alonso, M.J., 2005. PLA-PEG particles as nasal protein carriers: the influence of the particle size. International Journal of Pharmaceutics 292, 43-52. 
Zaman, M., Abdel-Aal, A.B., Fujita, Y., Ziora, Z.M., Batzloff, M.R., Good, M.F., Toth, I., 2012. Structure-activity relationship for the development of a self-adjuvanting mucosally active lipopeptide vaccine against Streptococcus pyogenes. Journal of medicinal chemistry $55,8515-8523$.

Zaman, M., Chandrudu, S., Giddam, A.K., Reiman, J., Skwarczynski, M., McPhun, V., Moyle, P.M., Batzloff, M.R., Good, M.F., Toth, I., 2014. Group A Streptococcal vaccine candidate: contribution of epitope to size, antigen presenting cell interaction and immunogenicity. Nanomedicine (London) 9, 2613-2624.

Zhou, J., Patel, T.R., Sirianni, R.W., Strohbehn, G., Zheng, M.Q., Duong, N., Schafbauer, T., Huttner, A.J., Huang, Y., Carson, R.E., Zhang, Y., Sullivan, D.J., Jr., Piepmeier, J.M., Saltzman, W.M., 2013. Highly penetrative, drug-loaded nanocarriers improve treatment of glioblastoma. Proceedings of the National Academy of Sciences of the United States of America 110, 11751-11756. 


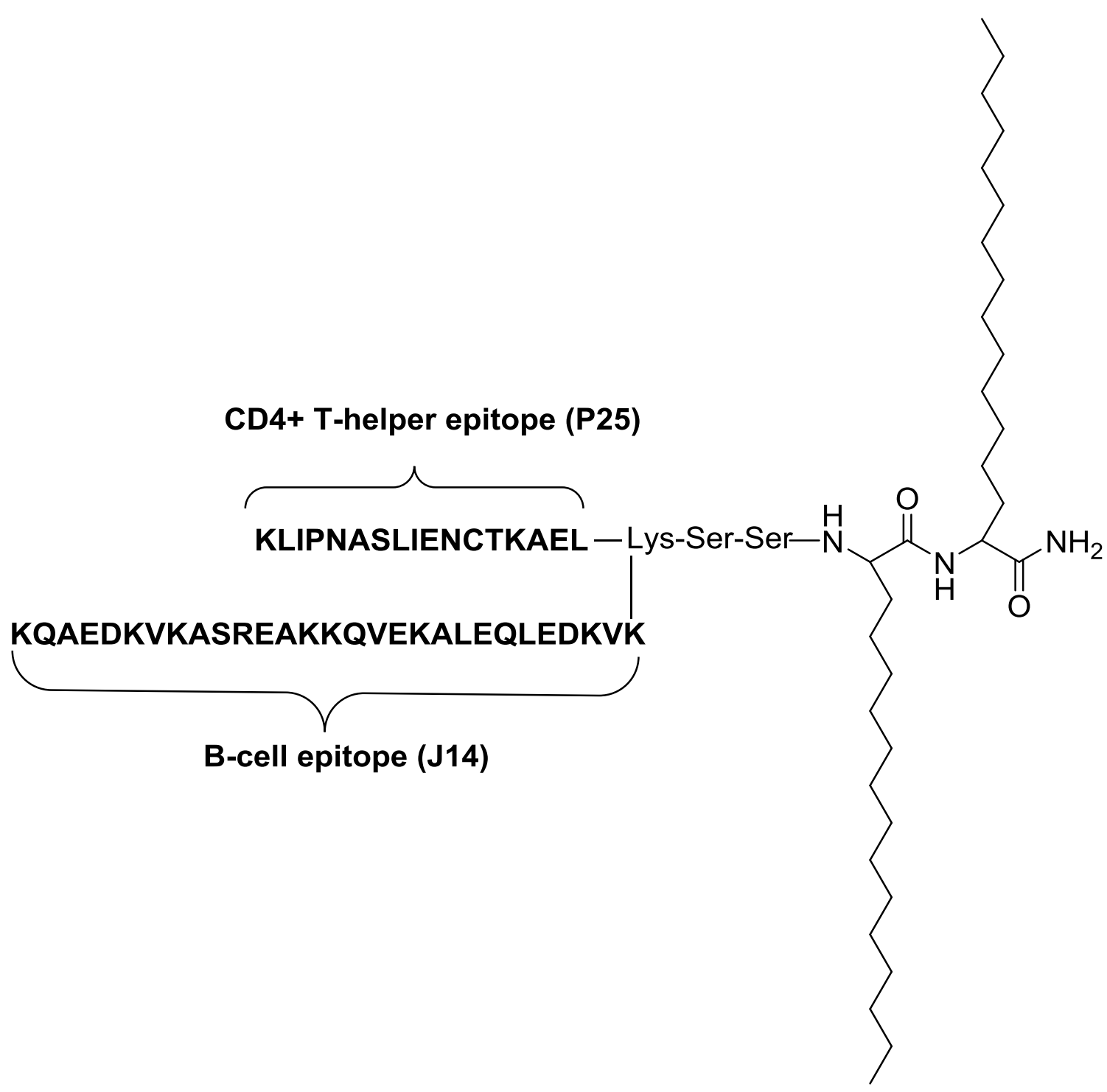

Figure 1. Chemical structure of lipid core peptide (LCP-1) vaccine candidate 
A

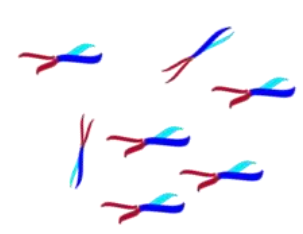

C

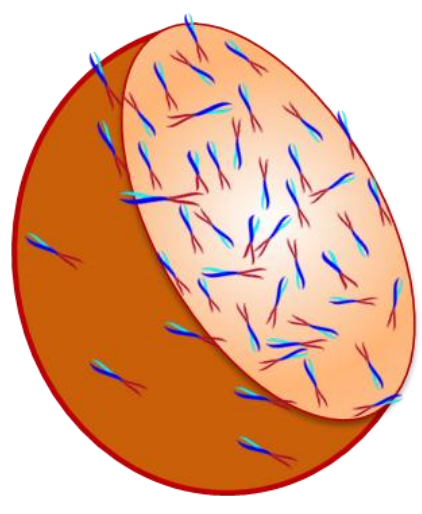

B

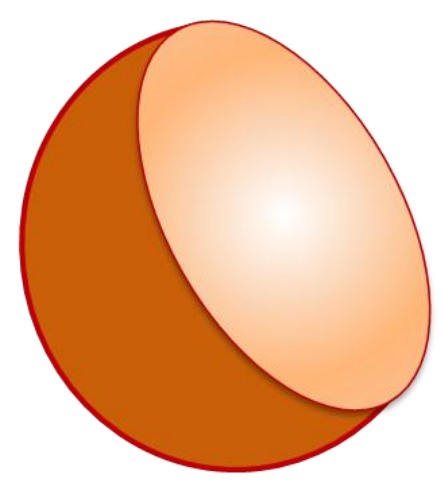

D

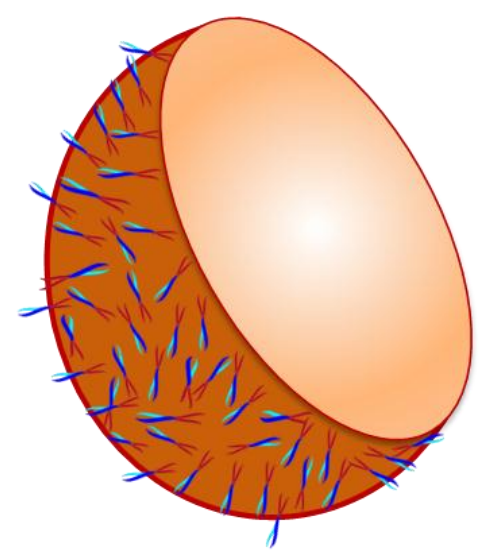

Figure 2. Schematic representation of vaccine formulations: (A) LCP-1, (B) Empty PLGA nanoparticle (C) LCP-1 encapsulated nanoparticle, NPs-1 and (D) LCP-1-coated nanoparticle, NPs-2. 

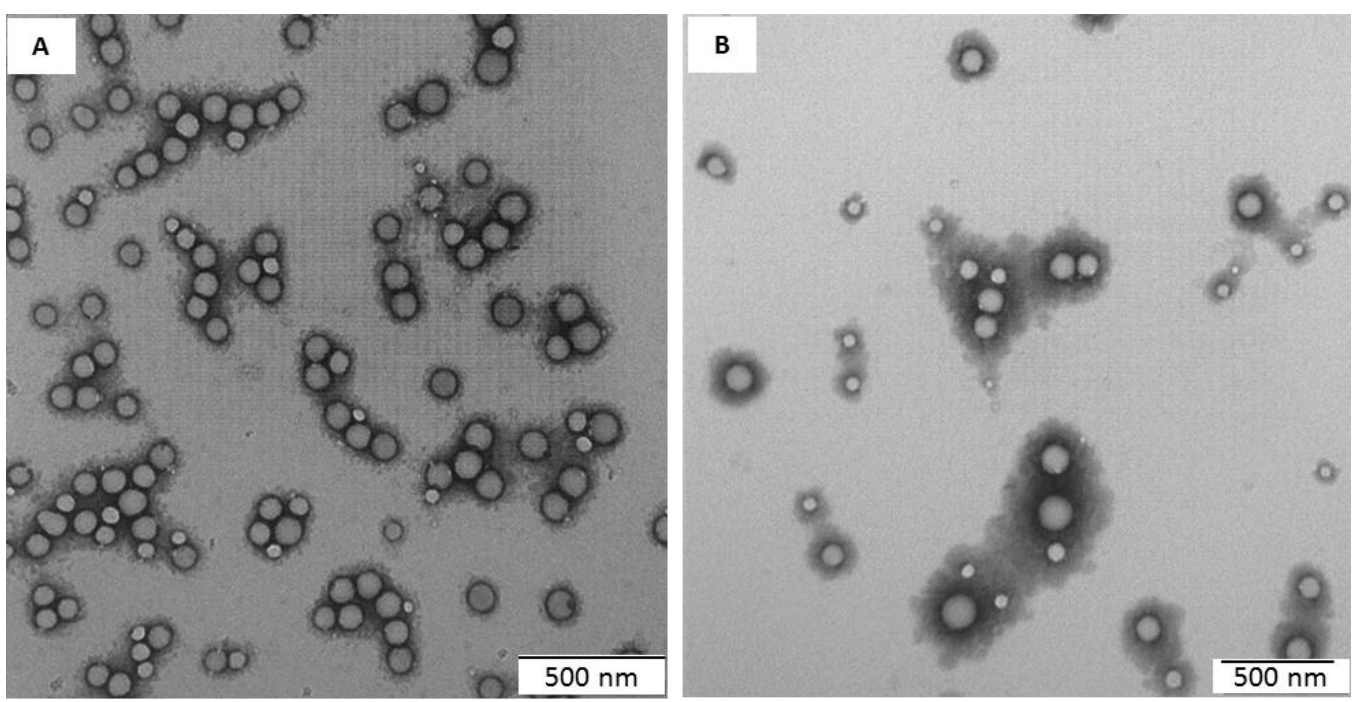

Figure 3. TEM images of nanoparticles: (A) LCP-1 encapsulated nanoparticles, NPs-1 and (B) LCP-1-coated nanoparticles, NPs-2. 


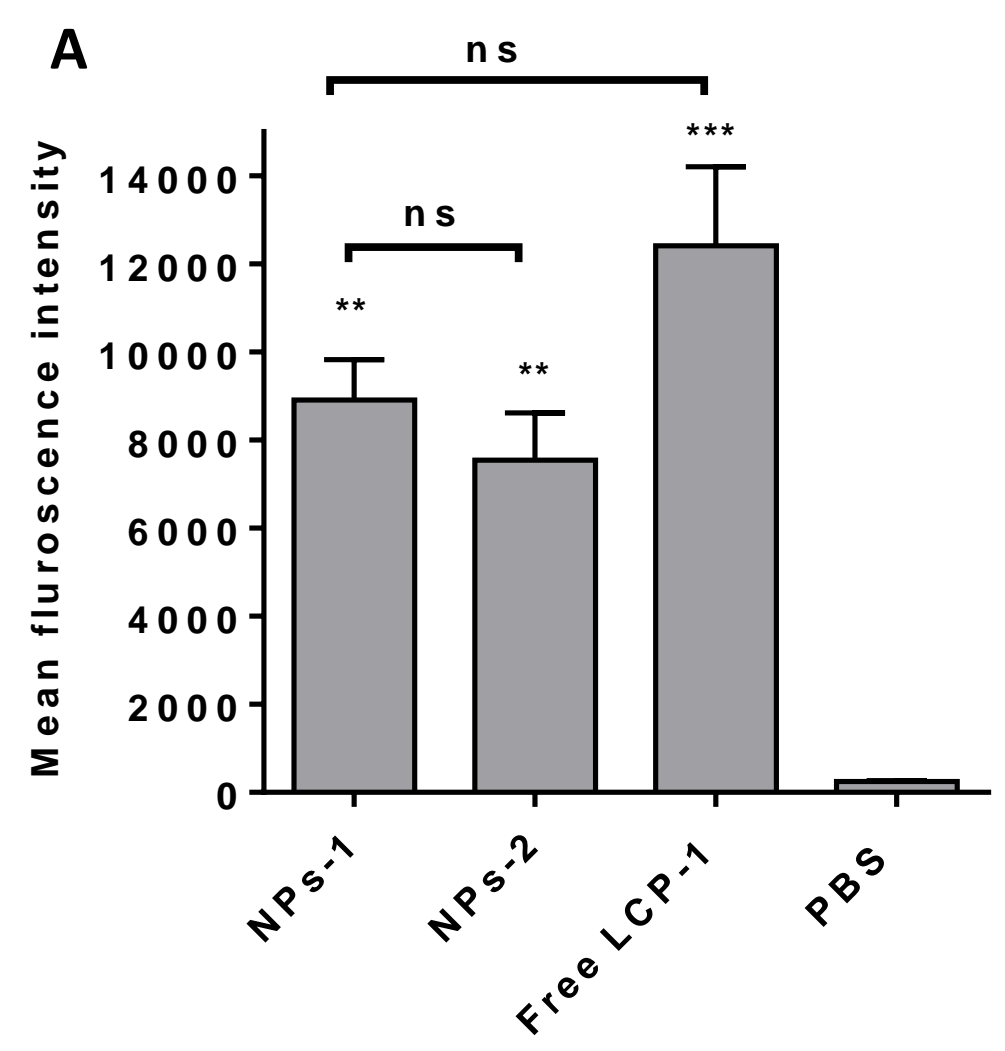

B

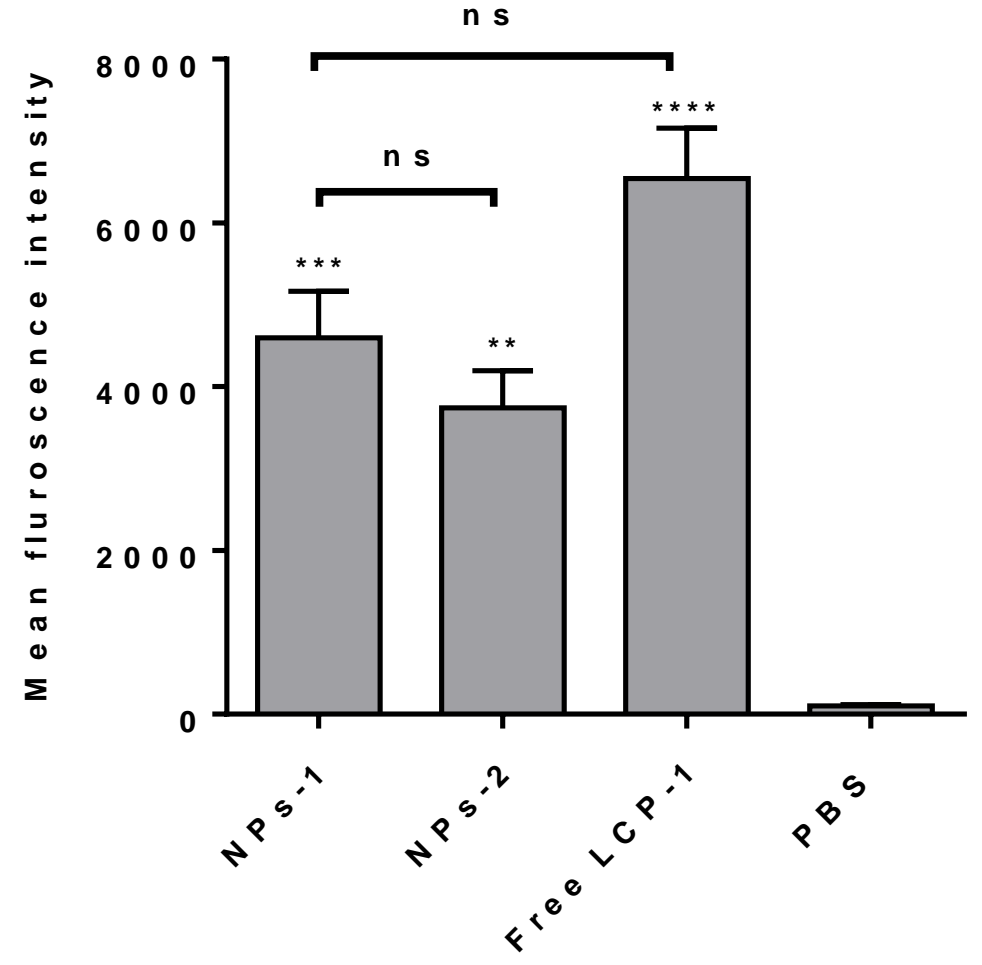

C

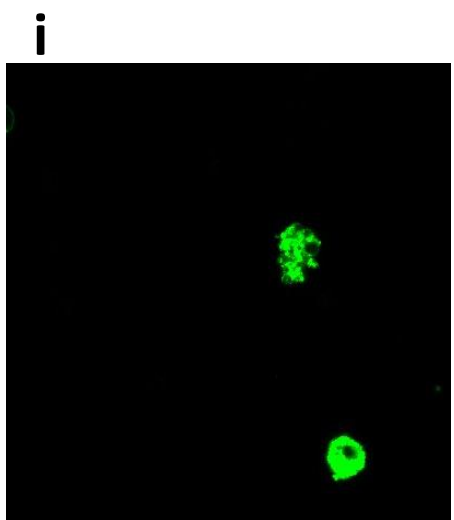

ii

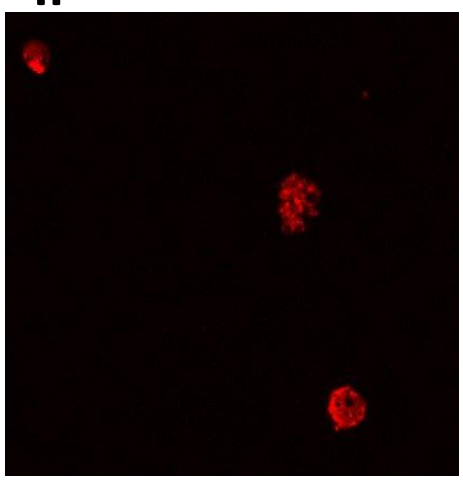

iii

iv
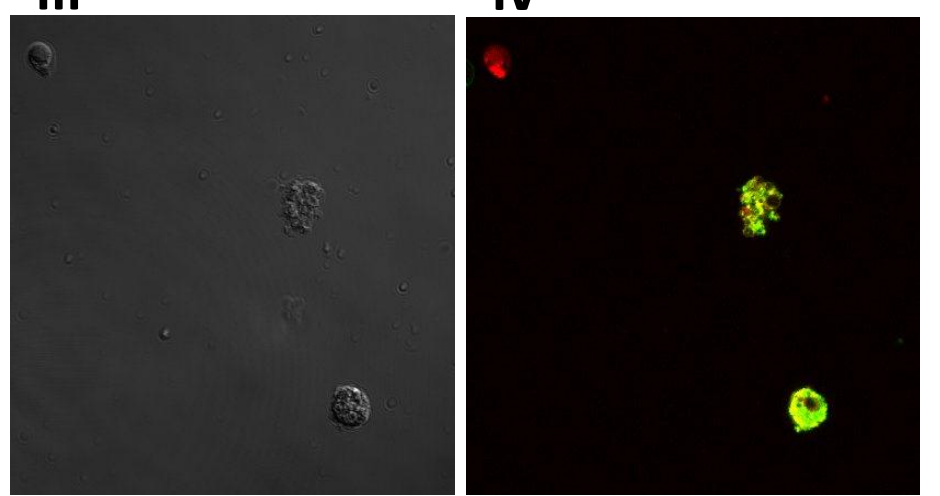
Figure 4. Flow cytometry comparison of vaccine formulations uptake by CD11c+ dendritic cells (A) and F4/80+ macrophages (B) $(n=3)$. Each bar represents the mean fluorescein intensity positive between carboxyfluroscein-LCP-1 and dendritic cell marker CD11c+ dendritic cells or F4/80+ macrophages. The differences between the groups were analysed using one-way ANOVA and post-hoc Tukey test. ns: $\mathrm{p}>0.05 ;{ }^{*} p<0.05$; ** $p<0.01$; *** $p<$ 0.001 ; $* * * p<0.001$. (C) Representative images showing co-localization of fluoresceintagged LCP-1 with complete splenocytes at $63 \times$ magnifications. The freshly isolated splenocytes were incubated with NPs-1 for $6 \mathrm{~h}$ at $37{ }^{\circ} \mathrm{C}$, washed and fixed with $4 \% \mathrm{w} / \mathrm{v}$ paraformaldehyde solution before observing them in a fluorescent microscope. (i) LCP-1 tagged with carboxyfluroscein (green colour) (ii) Lysotracker $^{\circledR}$ (red colour) stained cell endosomes, (iii) bright field and (iv) merged images (green + red). 

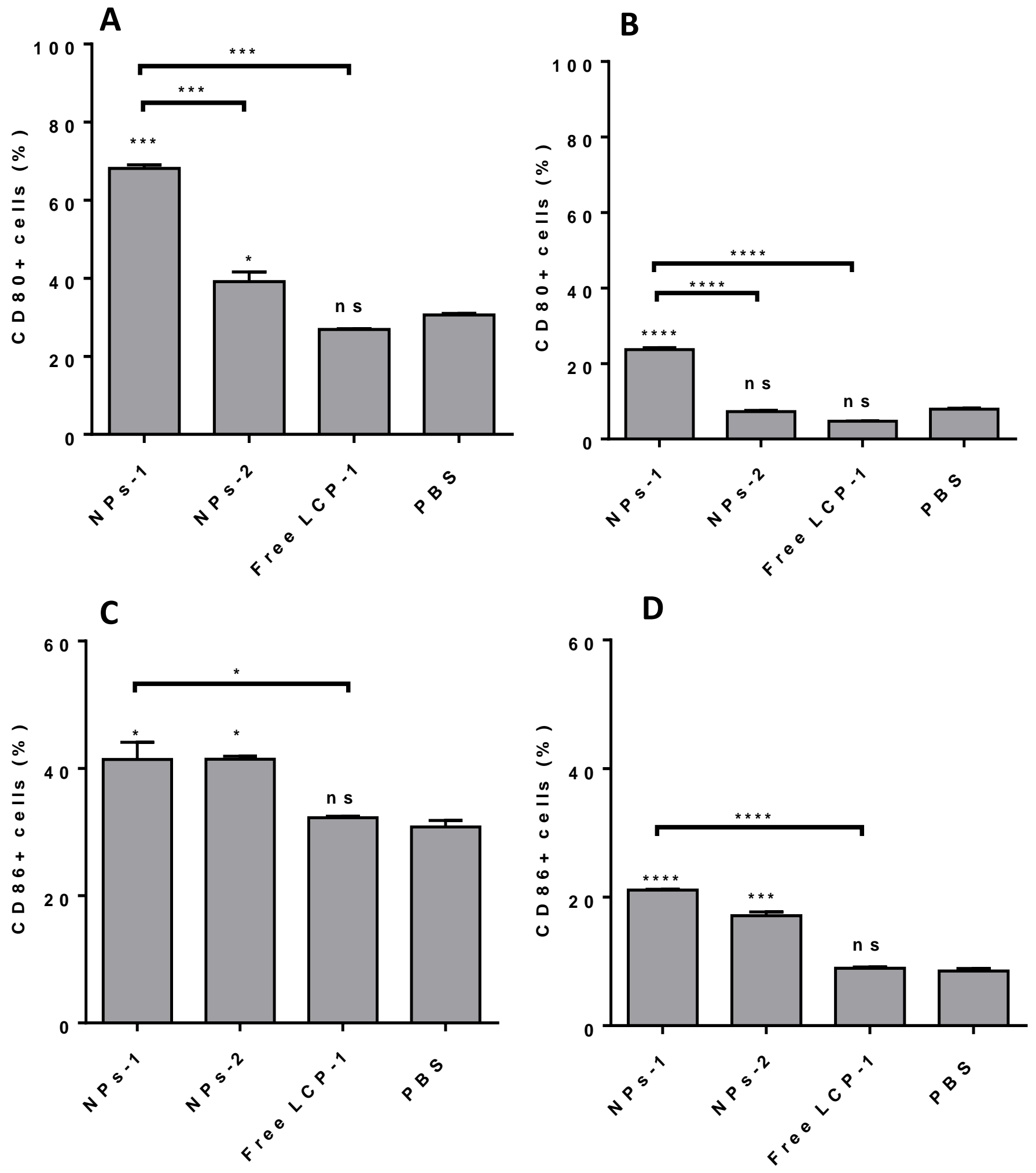

Figure 5. Flow cytometry comparison of expression of CD80 and CD86 maturation markers by mouse $\mathrm{CD} 11 \mathrm{c}^{+}$dendritic cells $\left(\mathrm{A}\right.$ and $\mathrm{C}$ ) and $\mathrm{F} 4 / 80^{+}$macrophages (B and $\mathrm{D}$ ) upon stimulating with vaccine formulations. Cells were tagged with dendritic cells marker CD11c and macrophage marker F4/80. Bar represents the percentage of cells double positive for 
$\mathrm{CD} 11 \mathrm{c}$ or $\mathrm{F} 4 / 80$ and $\mathrm{CD} 80$ or CD86. The differences between the groups were analysed using one-way ANOVA and post-hoc Tukey test. ns: $p>0.05 ;{ }^{*} p<0.05$; $* *<0.01$; $* * * p<0.001 ; * * * * p<0.001$. 
A

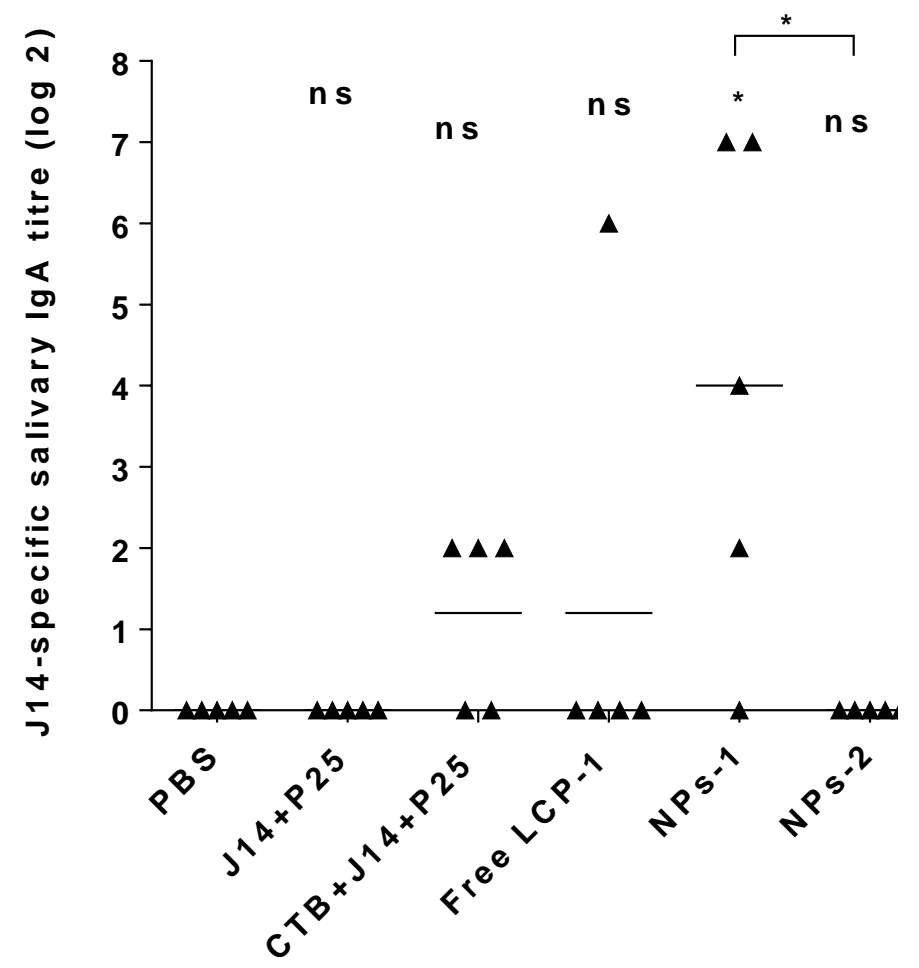

C

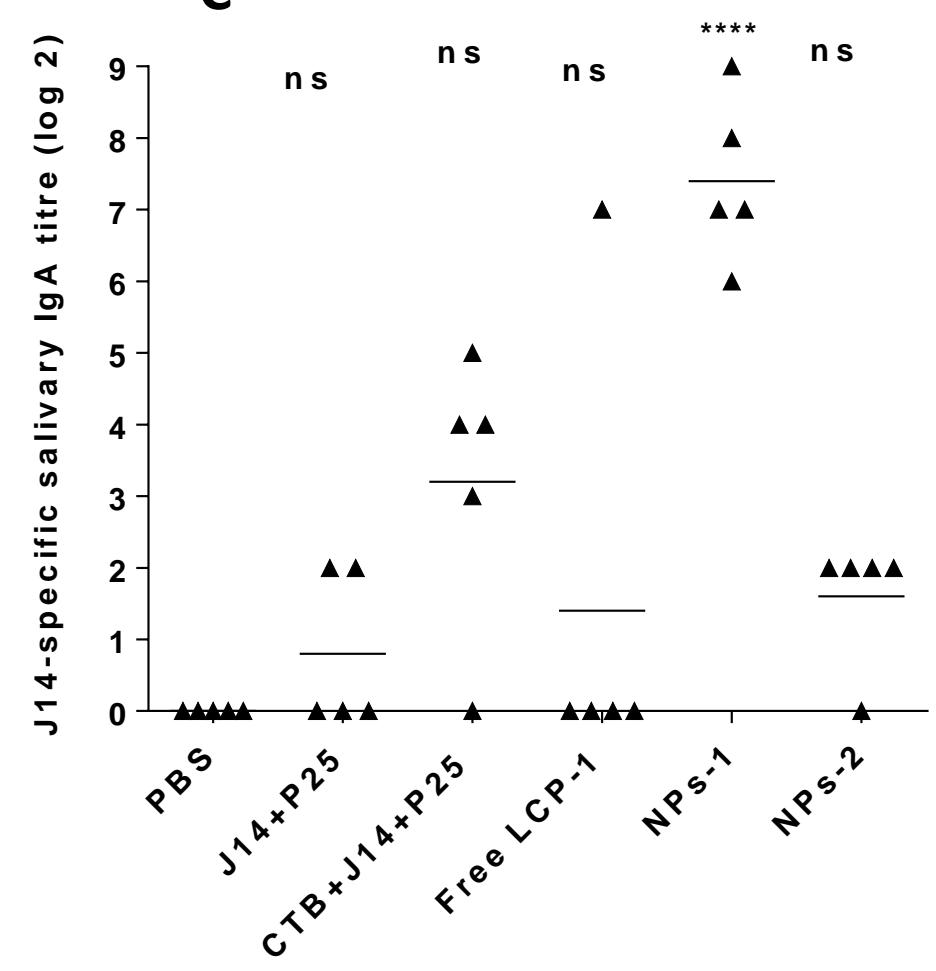

B

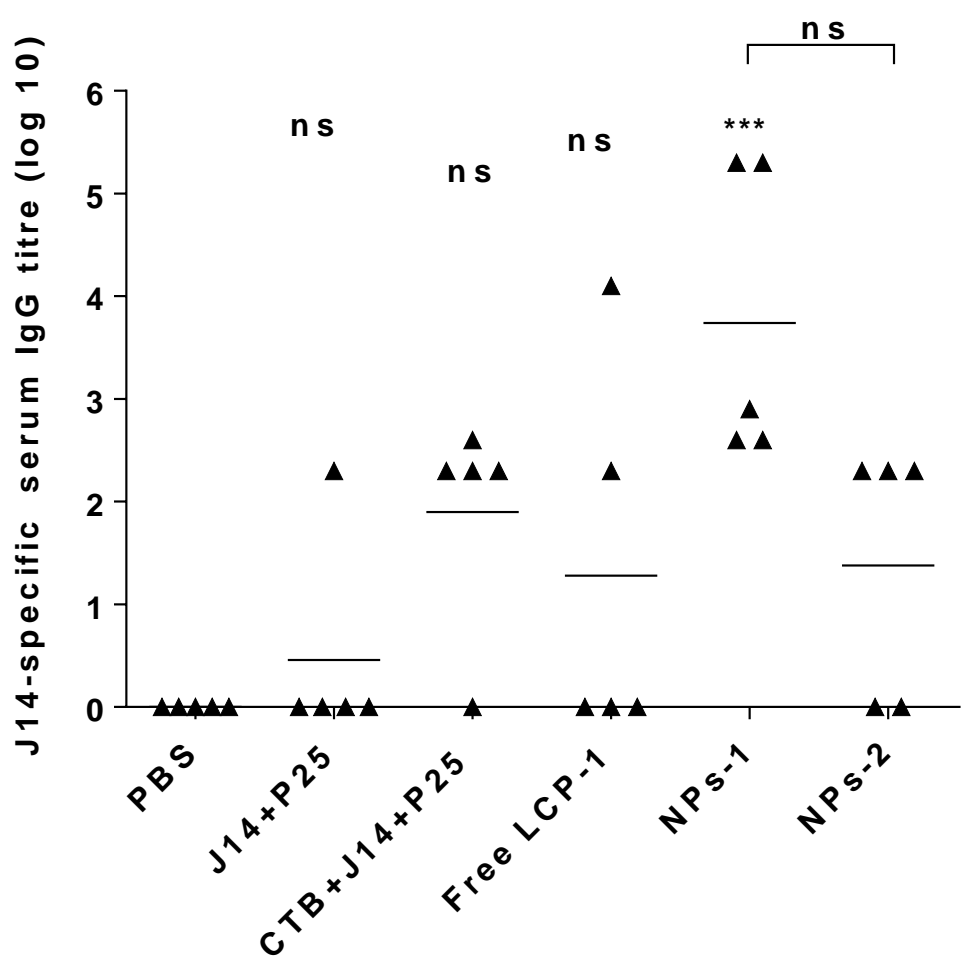

D

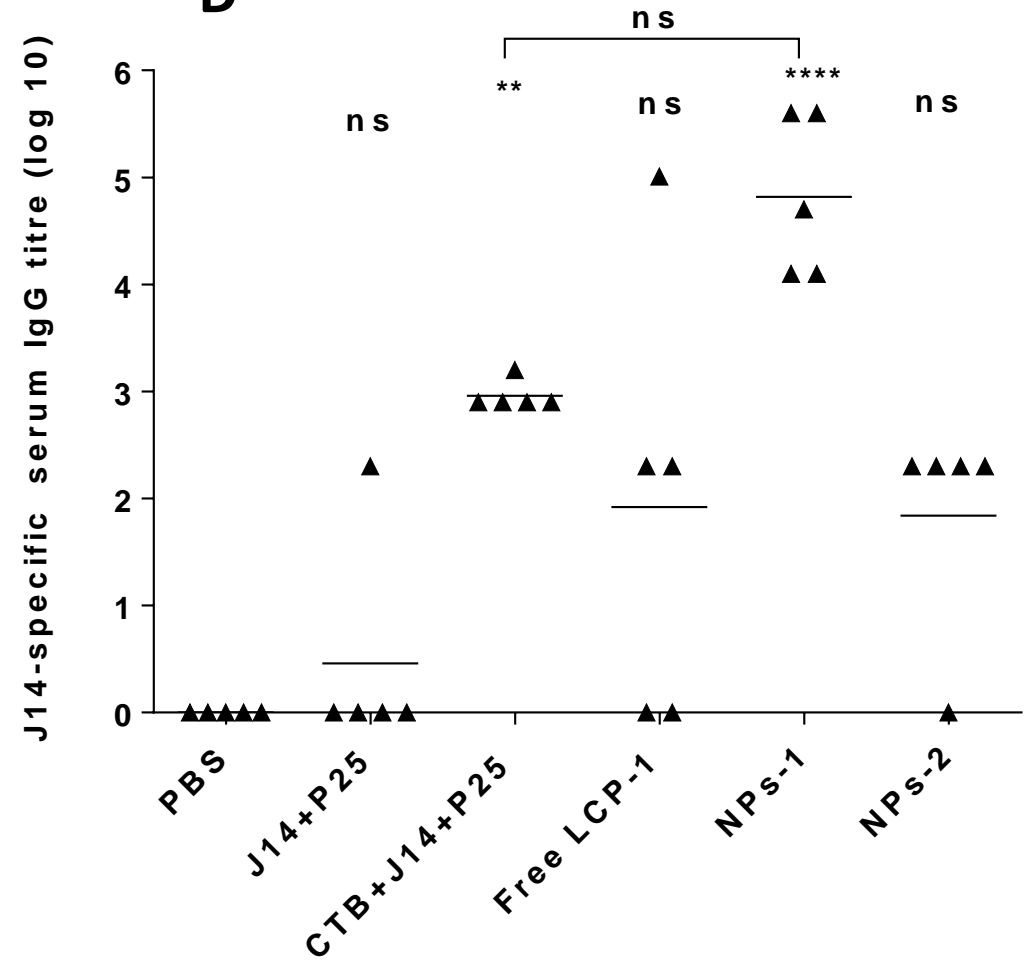


Figure 6. J14-specific antibody titres after following intranasal immunization with different vaccine formulations in outbred Swiss mice, as analysed by ELISA. (A) J14-specific IgA antibody titres in saliva after $1^{\text {st }}$ boosts (B) J14-specific IgG antibody titres in serum after $1^{\text {st }}$ boosts. (C) J14-specific IgA antibody titres in saliva after $2^{\text {nd }}$ boosts (D) J14-specific IgG antibody titres in serum after $2^{\text {nd }}$ boosts. Each point in the figure represents an individual mouse (5 mice/group); the mean J14-specific titres are represented as a bar. Statistical analysis was performed using one-way ANOVA followed by the post-hoc Tukey test compared with PBS as indicated (ns, $p>0.05 ; *, p<0.05$; **, $p<0.01$; ***, $p<0.001$ ). 


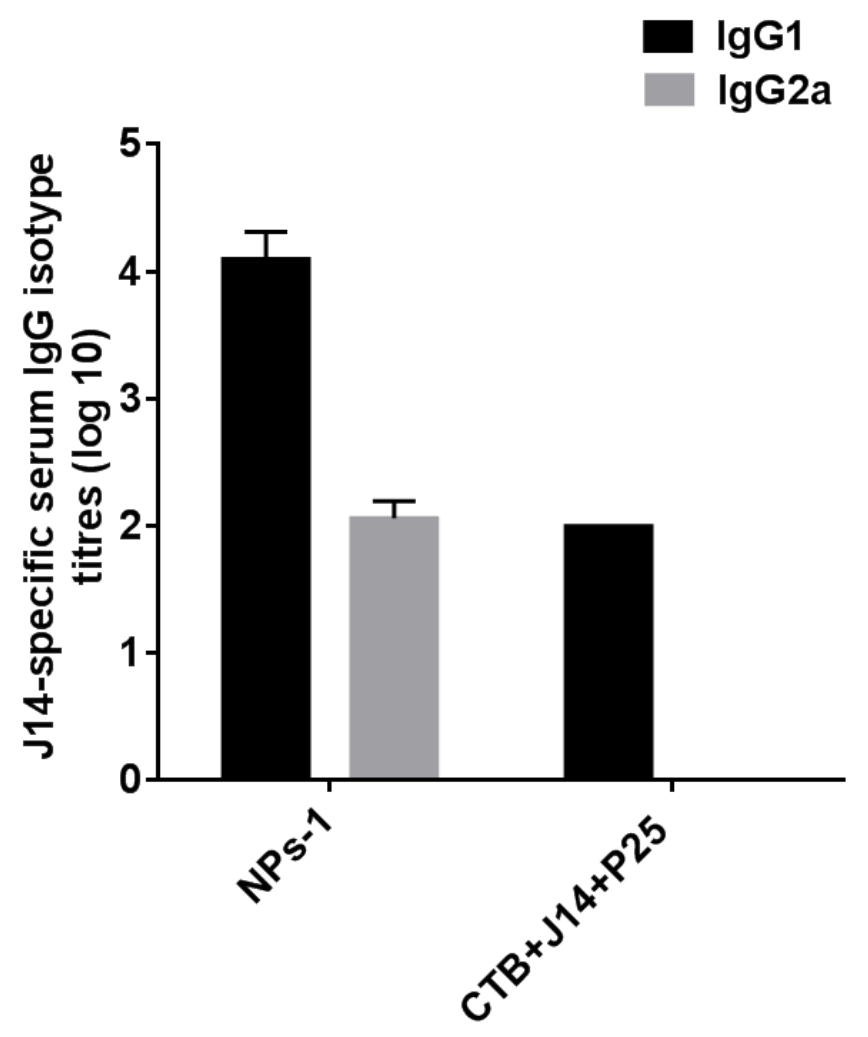

Figure 7. J14-specific serum $\operatorname{IgG}$ isotype titres $(\log 10)$ at $14^{\text {th }}$ day after $2^{\text {nd }}$ boosts upon intranasal immunization of Swiss mice. Error bar represents standard deviations $(n=5)$. 


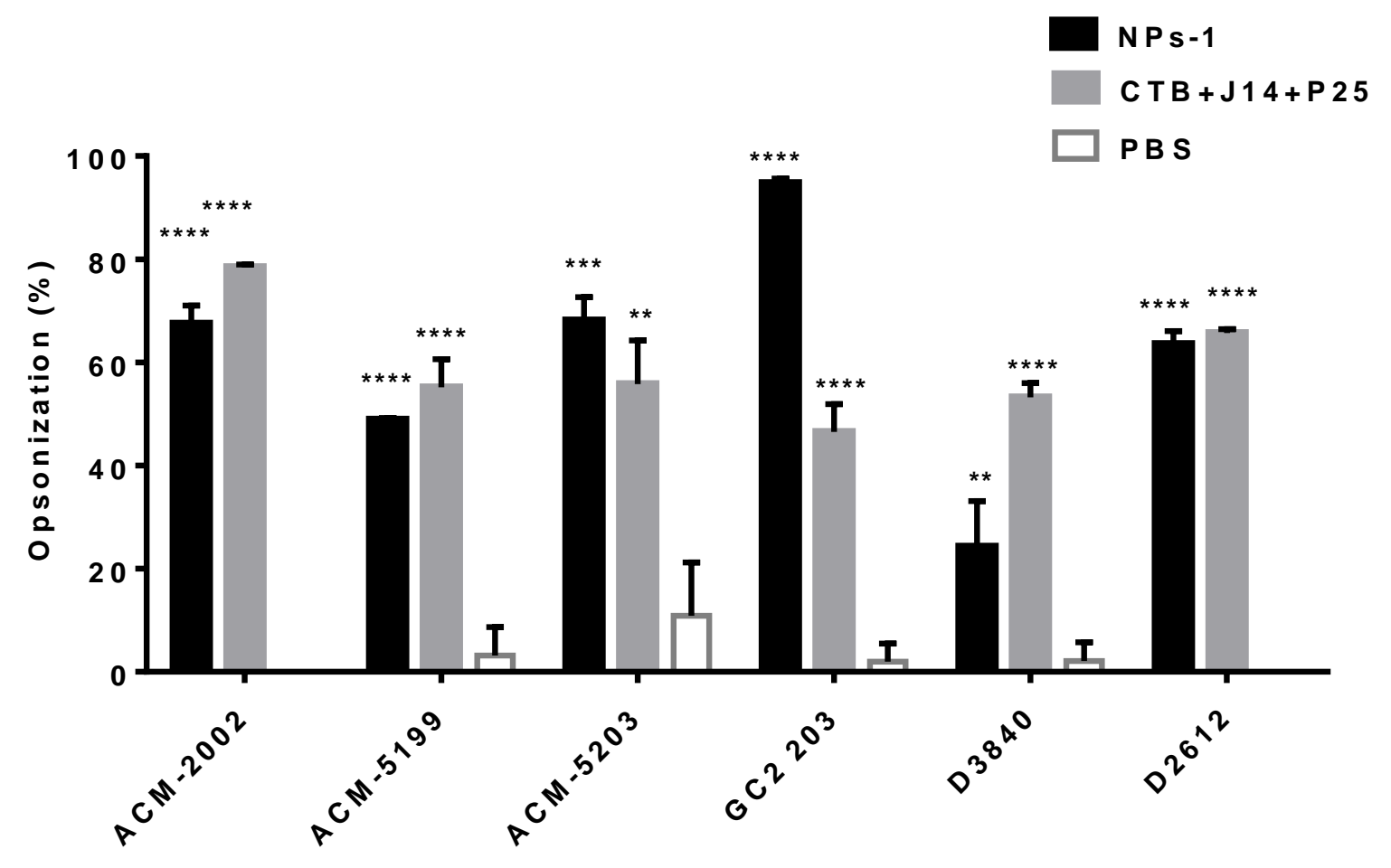

Figure 8. Average percentage opsonisation of different GAS strains by serum taken at day 60 after $2^{\text {nd }}$ boosts in Swiss mice $(n=3)$. Statistical analysis was performed using one-way ANOVA followed by the post-hoc Tukey test compared with PBS as indicated (ns, $p>0.05$; $*, p<0.05 ; * *, p<0.01 ; * * *, p<0.001)$. 
Table 1. List of various GAS strains used for bactericidal assay

\begin{tabular}{|l|l|}
\hline \multicolumn{1}{|c|}{ S.pyogenes strains } & \multicolumn{1}{c|}{ Culture site } \\
\hline ACM-2002 & $\begin{array}{l}\text { Royal Brisbane hospital, human abscess } \\
- \text { lymph gland }\end{array}$ \\
\hline $\begin{array}{l}\text { ACM-5199 = ATCC 12344, NCIB } \\
11841\end{array}$ & Scarlet fever \\
\hline ACM-5203 = ATCC 19615 & $\begin{array}{l}\text { Pharynx of child followed by episode of } \\
\text { sore throat }\end{array}$ \\
\hline GC2 203 & Wound swab \\
\hline D3840 & Naso-pharynx swabs \\
\hline D2612 & Naso-pharynx swabs \\
\hline
\end{tabular}


Table 2. Physicochemical characterizations of nanoparticles

\begin{tabular}{lcccccc}
\hline & $\begin{array}{c}\text { Particle } \\
\text { size }(\mathrm{nm})\end{array}$ & PDI & $\begin{array}{c}\text { Charge } \\
(\mathrm{mV})\end{array}$ & $\begin{array}{c}\text { Entrapment } \\
\text { efficiency } \\
(\%)^{\mathrm{a}}\end{array}$ & $\begin{array}{c}\text { Loading } \\
\text { efficiency } \\
(\%)^{\mathrm{b}}\end{array}$ & $\begin{array}{c}\text { Yield } \\
(\%)^{\mathrm{c}}\end{array}$ \\
\hline Empty NPs & $205 \pm 0.2$ & $0.063 \pm 0.03$ & $-32.8 \pm 0.5$ & - & - & \\
& & & & & & \\
NPs-1* & $198 \pm 1.2$ & $0.248 \pm 0.04$ & $7.7 \pm 2.6$ & $71.4 \pm 0.5$ & $27.7 \pm 0.2$ & 5.7 \\
& & & & & & \\
NPs-2** & $219 \pm 3.5$ & $0.120 \pm 0.03$ & $-4.5 \pm 0.2$ & $29.5 \pm 3.0$ & $11.5 \pm 1.2$ & 6.3 \\
& & & & & & \\
\hline
\end{tabular}

*LCP-1 vaccine candidate encapsulated into NPs

**LCP-1 vaccine candidate surface-adsorbed onto NPs

a Entrapment efficiency (\%): weight of LCP-1 in nanoparticles / weight of LCP-1 fed initially $\times 100$

${ }^{\mathrm{b}}$ Loading efficiency (\%): weight of LCP-1 in nanoparticles /weight of nanoparticles $\times 100$

${ }^{c}$ Nanoparticle yield calculated from supernatant obtained after 3,000 $\times g$ for 3 min followed by second centrifugation at $15,000 \times g$ for 10 min followed by freeze-drying using following formula: Nanoparticle yield $(\%)=$ weight of nanoparticles/weight of polymers + LCP-1 fed initially $\times 100$ 


\section{Accepted Manuscript}

Title: Lipid core peptide/poly(lactic-co-glycolic acid) as a highly potent intranasal vaccine delivery system against Group A streptococcus

Author: Nirmal Marasini Zeinab G. Khalil Ashwini Kumar Giddam Khairunnisa Abdul Ghaffar Waleed M. Hussein

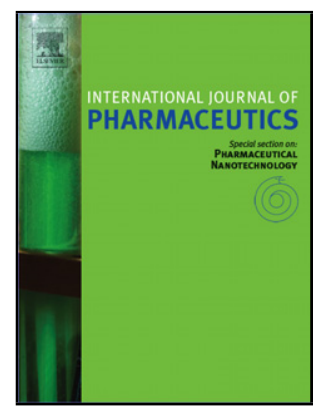
Robert J. Capon Michael R. Batzloff Michael F. Good Mariusz Skwarczynski Istvan Toth

$\begin{array}{ll}\text { PII: } & \text { S0378-5173(16)30887-0 } \\ \text { DOI: } & \text { http://dx.doi.org/doi:10.1016/j.ijpharm.2016.09.057 } \\ \text { Reference: } & \text { IJP 16099 }\end{array}$

To appear in: $\quad$ International Journal of Pharmaceutics

Received date: 1-6-2016

Revised date: $\quad$ 15-9-2016

Accepted date: $\quad$ 19-9-2016

Please cite this article as: Marasini, Nirmal, Khalil, Zeinab G., Giddam, Ashwini Kumar, Ghaffar, Khairunnisa Abdul, Hussein, Waleed M., Capon, Robert J., Batzloff, Michael R., Good, Michael F., Skwarczynski, Mariusz, Toth, Istvan, Lipid core peptide/poly(lactic-co-glycolic acid) as a highly potent intranasal vaccine delivery system against Group A streptococcus.International Journal of Pharmaceutics http://dx.doi.org/10.1016/j.ijpharm.2016.09.057

This is a PDF file of an unedited manuscript that has been accepted for publication. As a service to our customers we are providing this early version of the manuscript. The manuscript will undergo copyediting, typesetting, and review of the resulting proof before it is published in its final form. Please note that during the production process errors may be discovered which could affect the content, and all legal disclaimers that apply to the journal pertain. 